\title{
SPATIAL MODELING OF SOIL SALINITY USING MULTIPLE LINEAR REGRESSION, ORDINARY KRIGING AND ARTIFICIAL NEURAL NETWORK METHODS IN THE LOWER CHELIFF PLAIN, ALGERIA
}

\author{
Koulla Noureddine 1-2, Achite Mohammed ${ }^{3 *}$, Celso A. G. Santos ${ }^{4}$, Douaoui Abdelkader2-5, \\ Bradaï Abdelhamid ${ }^{3}$ and Thiago Victor M. do Nascimento ${ }^{4}$ \\ ${ }^{1}$ Faculty of Nature and Life Sciences, University Hassiba Benbouali of Chlef, Chlef, Algeria \\ ${ }^{2}$ Laboratory of Agricultural Production and Sustainable Valorisation of Natural Resources, Algieria Khemis \\ Meliana University \\ ${ }^{3}$ Faculty of Nature and Life Sciences, Laboratory of Water \& Environment, University Hassiba Benbouali of Chlef, \\ Chlef, Algeria \\ ${ }^{4}$ Department of Civil and Environmental Engineering, Federal University of Paraíba, Brazil \\ ${ }^{5}$ University Center Morsli Abdellah, Tipaza 42000, Algeria
}

Received 24 August 2019; received in revised form 12 September 2019; accepted 12 September 2019

\begin{abstract}
Soil salinity is one of the most damaging environmental issues worldwide, essentially in arid and semi-arid regions, caused by various factors. Spatial estimation and prediction of salinity is important to predict land evaluation in order to develop and determine leaching factor and the precise management for maximum production. The Lower Cheliff is characterized by the augmentation of rate of soil salinity in $80 \%$ of area. In this study, the relationship between both elevation and soil salinity was analysed, giving their role in understanding and estimating the spatial distribution of soil salinity in the Lower Cheliff plain. To conduct this work, 406 samples were taken and analysis of electric conductivity was performed as well as the measurement of the elevation using a GPS. The correlations of soil salinity with elevation were analysed as well. In this study, a great focus on the use of the multiple linear regressions, ordinary kriging and artificial neural network methods was given. The results showed that soil salinity had a good correlation with elevation, and according to the values of coefficient of determination $\left(\mathrm{R}^{2}\right)$, root mean square error (RMSE) and mean absolute error (MAE), the superiority of MLP model was implied with the value of $\mathrm{R}^{2}=0.994$, $\mathrm{RMSE}=0.63$ and $\mathrm{MAE}=0.33$.
\end{abstract}

Keywords: ANN; soil salinity; Lower Cheliff; ordinary kriging; regression

(C) 2019 Journal of Urban and Environmental Engineering (JUEE). All rights reserved.

\footnotetext{
* Correspondence to: Achite Mohammed, Tel.: +213 5514243 33, +213661 715456.

E-mail: achitemohammed@gmail.com
} 


\section{INTRODUCTION}

Soil salinity is caused by two different factors, i.e. natural and human-induced processes which makes it a major environmental hazard, and one of the main causes of land degradation and many other great problems like productivity loss, severe economic and social consequences (Ayetiguli et al., 2014). According to FAO (2010), more than $6 \%$ of world soil resources are affected by salt (Fuqiang et al., 2014). It became well known that the global extent of primary salt-affected soils is approximately $955 \mathrm{Mha}$, whereas secondary salinization affects approximately 77 Mha (Wang et al., 2012). In arid and semi-arid regions, soil salinization is one of the most critical environmental problems (Jianli \& Danlin, 2014; Ping et al., 2010; Fernandez et al., 2006).

In Algeria, the salinity has increased significantly in the last decade, and the lower Chéliff is one of the most heavily affected regions by the soil salinity problems with over $80 \%$ due to irrigation activities (Douaoui et $a l ., 2006)$. Monitoring soil salinity is very important for planning and implementing agronomic and irrigation practices (Scudiero et al., 2017). Soil salinity varies severely over time and space and depends on various factors such as climate, land use and topography (Shahabi et al., 2016).

There are many worldwide researches related to prediction of soil salinity, e.g. assessing soil salinity using soil salinity and vegetation indices derived from IKONOS high-spatial resolution imageries, applications in a date palm dominated region (Allbed et al., 2014); remote sensing of soil salinity: potentials and constraints (Metternicht \& Zinck, 2003); GIS-mapping spatial distribution of soil salinity for Eco-restoring the Yellow River Delta in combination with electromagnetic induction (Guangming et al., 2016); quantitative analysis of salt-affected soil reflectance spectra: a comparison of two adaptive methods (PLSR and ANN) (Farifteh et al., 2007); improved spatiotemporal monitoring of soil salinity using filtered kriging with measurement errors: an application to the West Urmia Lake, Iran (Hamzehpour et al., 2017); predicting ESP and SAR by artificial neural network and regression models using soil $\mathrm{pH}$ and electrical conductivity (EC) data (Miankangi Region, Sistan and Baluchestan Province, Iran) (Sarani et al., 2015); modelling of soil salinity within a semi-arid region using spectral analysis (Fourati et al., 2015); spatial modelling of soil salinity using multiple linear regression, ordinary kriging and artificial neural network methods (Shahabi et al., 2016); in addition to the studies on the nonlinear relationship between soil salinity and topography factors (Wang et al., 2008; Sarani et al., 2015).

This study came up with a whole new perspective on the integration of new variables in soil salinity prediction, giving more significance and even more accuracy to the prediction of soil salinity in one specific area which is the Lower Cheliff plain. Thus, an artificial neural network approach was developed for soil salinity prediction based on EC data and the elevation that have already shown a very good individual correlation. Finally, the accuracy of ANN models with the ordinary kriging and regression models was compared using three statistical performance criteria: coefficient of determination $\left(\mathrm{R}^{2}\right)$, the root mean square error (RMSE), and the mean absolute error (MAE).

\section{MATERIALS AND METHODS}

\section{Study area}

The Lower Chéliff Plain is located in north-western Algeria, between longitude $0^{\circ} 40^{\prime}$ and $01^{\circ} 06^{\prime} 08^{\prime \prime} \mathrm{E}$ and latitudes $34^{\circ} 03^{\prime} 12^{\prime \prime}$ and $36^{\circ} 05^{\prime} 57^{\prime \prime} \mathrm{N}$ (Fig. 1). It is situated approximately $40 \mathrm{~km}$ inland of the Mediterranean. This Plain covers an area of approximately 40000 ha and is characterized by a semiarid climate with very hot summers, low winter temperatures and a mean annual rainfall of $250 \mathrm{~mm}$ and temperature range from 12 to $38^{\circ} \mathrm{C}$. The mean annual pan evaporation (potential evaporation) depth is about $1500 \mathrm{~mm}$ (Douaoui, 2005), and the elevation varies between 30 and $150 \mathrm{~m}$.

\section{Soil sampling and laboratory analysis}

Soil data were collected at 410 soil sample locations. Figure 2 shows that these locations were selected across the study field to account for the variation in EC and elevation. One sample was obtained at each location and were located using a GPS. This sample was collected from the topsoil (0-20 cm depth) (Douaoui et al., 2006; Inakwu \& Alex, 2008; Shahabi et al., 2015). Soil sampling was undertaken using a hand auger; at the time of sampling the soil was placed into polyethylene bags. The soil samples transported to the laboratory were air-dried and passed through a $2 \mathrm{~mm}$ sieve before analysis. Electrical conductivity was both determined from a measurement of the saturated paste salinity, with two replicated analysis per sample by using a conductivimeter (Rhoades, 1982).

\section{Models used to estimate electrical conductivity}

In this work, five regressive models were used, which are showed in Eqs (1) to (5), i.e. the linear model, the parabolic model, the exponential model, the power model, and the logarithmic model, respectively.

$$
\begin{gathered}
Y=a+b X \\
Y=a+b X+c X^{2} \\
Y=b \mathrm{e}^{a X} \\
Y=b X^{a} \\
Y=a+b \ln (X)
\end{gathered}
$$



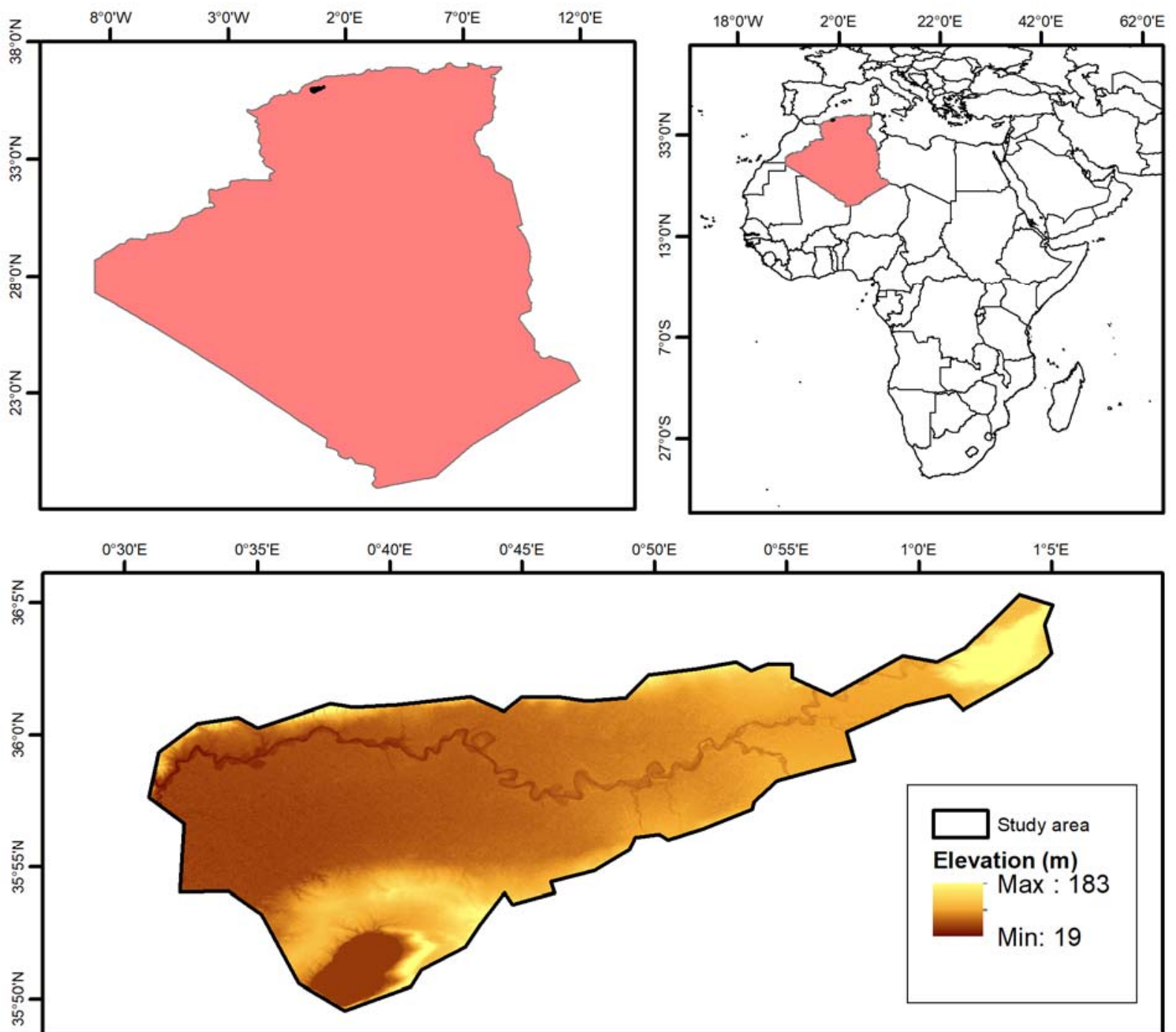

Coordinate System: GCS WGS 1984 Datum: WGS 1984 Units: Degree

Fig. 1 Location of the Lower Cheliff plain, Algeria.

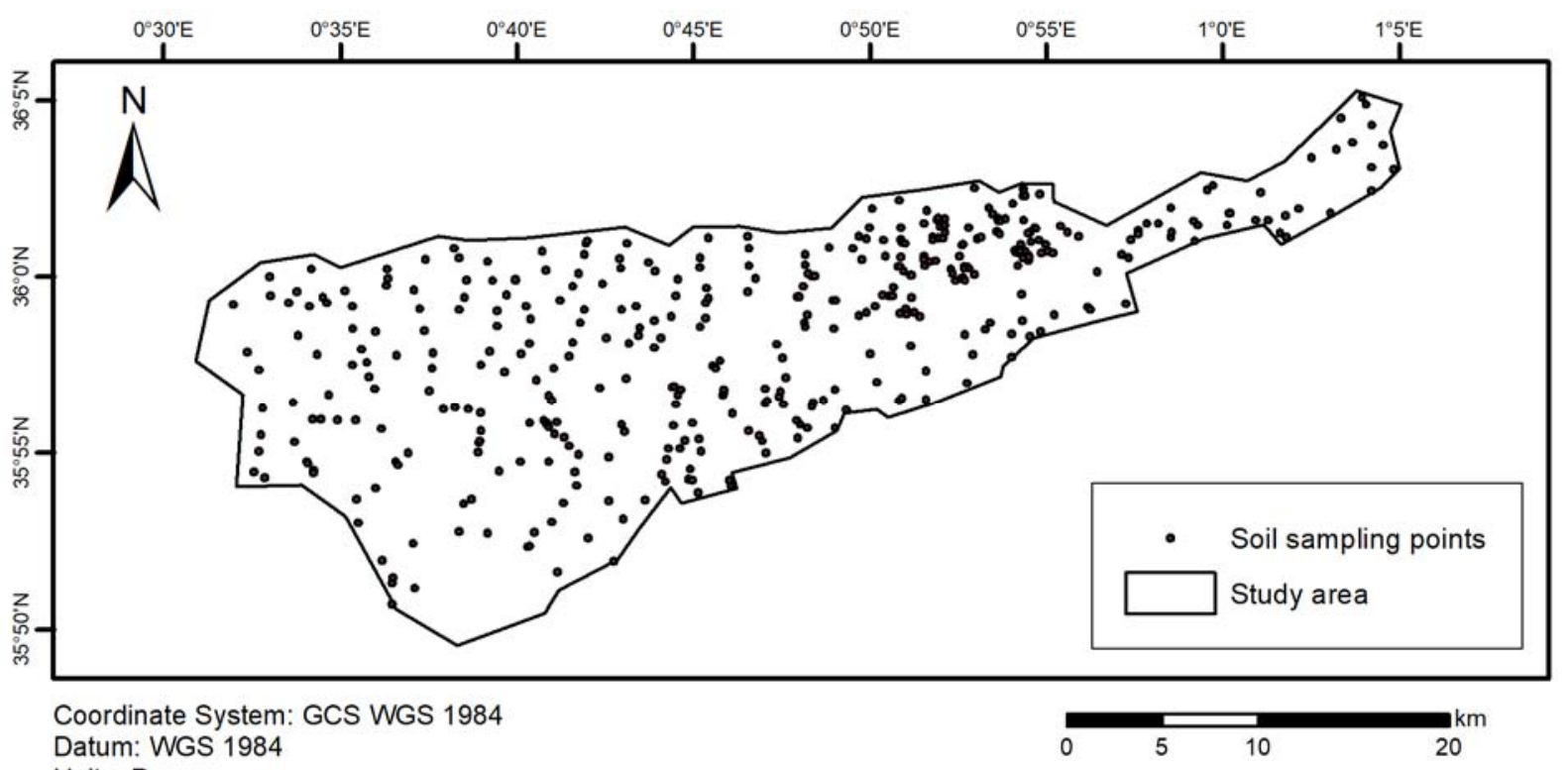

Fig. 2 Distribution of soil sampling points in the study area. 
where $Y$ is the dependent variable (EC), $X$ is the independent variable $(Z), b$ is the regression coefficient, and $a$ is the intercept.

\section{Multiple linear regressions (MLR)}

Multiple linear regressions are a generalization, with $p$ explanatory variables, of simple linear regression. It stays within the framework of the mathematical regression: to a given sample $\left(Y_{i}, X_{i 1}, \ldots X_{i p}\right)$, we try to explain as accurate as possible, the values taken by $Y_{i}$, so-called endogenous variable, from a series of explanatory variables $X_{i 1}, \ldots X_{i p}$. Equation (6) is the formula for the model of multiple linear regression.

$$
Y_{i}=a_{0}+a_{1} X_{i 1}+a_{2} X_{i 2}+\cdots+a_{p} X_{i p}+b
$$

where $Y_{i}$ is the dependent variable and $X_{i}$ is the independent variable, $a$ are the regression coefficients, and $b$ is the intercept.

\section{Ordinary kriging (OK)}

The spatial estimate of salinity was made by ordinary kriging, which allows the estimation of a $Z$ property at any point in the $x_{0}$ coordinate space by a linear combination of observations made at near points $x_{i}$. Equation (7) shows it, and Eq. (8) shows the sum value of the weight.

$$
\begin{gathered}
Z\left(x_{0}\right)=\sum_{i=1}^{n} \lambda_{i} Z\left(x_{i}\right) \\
\sum_{i=1}^{n} \lambda_{i}=1
\end{gathered}
$$

where $n$ is the number of points $x_{i}$ and $\lambda_{i}$ is the weight assigned to each neighbour.

The parameters of the spatial structure of the kriger variable are determined from the adjustment of the variogram to a theoretical model (spherical, exponential, etc.) which, in the intrinsic hypothesis is:

$$
\gamma(h)=\frac{1}{2 N(h)} \sum_{i=1}^{N(h)}\left[Z\left(x_{i}\right)-Z\left(x_{i}+h\right)\right]^{2}
$$

where $\gamma(h)$ is the semi-variance for a distance $h$; $N$ is the number of pairs of observations separated by the distance $h ; Z\left(x_{i}\right)$ is the regional variable value at point $i$; $Z\left(x_{i}+h\right)$ is the regional variable value of other points separated from $x_{i}$.

\section{Artificial neural network (ANN)}

A neural network consists of cells (or neurons) connected to each other by weight-assigned links. These possible cells link to each channel eliminator cell to send and receive signals from other cells in the network. Each of these connections receives a weight, which determines its impact on the cells it connects. Each cell thus has an input, which allows it to receive information from other cells, but also from what is called an activation function, which in the simplest cases is a simple identity of the result obtained by the input and finally an output (Santos \& Silva, 2014; Freire et al., 2019; Santos et al., 2019; Honorato et al., 2019).

\section{Multilayer perceptron network (MLP)}

They are networks in which the information flow propagates from the input layer to the hidden layers until the output, without going back. An unbound neuron network performs one or more functions of its inputs by composition of the functions performed by each of the neurons (Dreyfus, 2002). The multilayered perceptron is the most widely used neural network model, consisting of three adjacent, concealed, entrapped layers and outlets where each layer contains multiple neurons (Boukhatem et al., 2012). Multilayer perceptron is a neural network that has more than one hidden layer between the input and output layers, and each layer contains computational units (neurons) connected to other neurons by weights (Rumelhart et al., 1986; Yang et al., 2003).

\section{Radial basis function networks (RBF)}

The architecture of a neural network with spherical activation units is called a radial basic function network or RBF network. A network without feedback typically has a single layer of hidden units. The RBF networks are also good at modelling nonlinear data.

\section{Normalization of data}

The input data of the neural network have different quantitative limits, then the normalization of the data is necessary; there are several linear translations that can be used to normalize this data between -1 and 1 . The most used procedure was applied here:

$$
x_{n}=\frac{\left(x_{i}-x_{\min }\right)}{\left(x_{\max }-x_{\min }\right)}
$$

where $x_{i}, x_{n}, x_{\min }$ and $x_{\max }$ are respectively the input, normalized, minimum and maximum values.

The performance of each model was studied under the statistical performance criteria of the coefficient of determination $\left(\mathrm{R}^{2}\right)$, the root mean square error (RMSE), and the mean absolute error (MAE). The values of each model were compared with measured electrical conductivity (EC). The statistical indices are defined as follows:

$$
\mathrm{R}^{2}=1-\frac{\sum_{i=1}^{N}\left(\mathrm{EC}_{i \text { (measured })}-\mathrm{EC}_{i(\text { model })}\right)}{\sum_{i=1}^{N}\left(\mathrm{EC}_{i \text { (measured })}-\mathrm{EC}_{\text {mean }}\right)}
$$


The root mean square error (RMSE) is used to decide the best model and is defined as:

$$
\mathrm{RMSE}=\sqrt{\frac{1}{N} \sum_{i=1}^{N}\left(\mathrm{EC}_{i(\text { measured })}-\mathrm{EC}_{i(\text { model })}\right)}
$$

The mean absolute error (MAE) is defined as:

$$
\mathrm{MAE}=\frac{1}{N} \sum_{i=1}^{N}\left|\left(\mathrm{EC}_{i(\text { measured })}-\mathrm{EC}_{i(\text { model })}\right)\right|
$$

where $N$ is the number of measured $\mathrm{EC}$ data, $\mathrm{EC}_{i \text { (measured) }}$ and $\mathrm{EC}_{i \text { (model) }}$ are the measured and modelled $\mathrm{EC}$, respectively, and $\mathrm{EC}_{\text {mean }}$ is the mean of measured $\mathrm{EC}$.

\section{RESULTS AND DISCUSSION}

The main statistical parameters for the electrical conductivity (EC), for the all data are given in Table 1, where $\mathrm{EC}_{\mathrm{a}}$ is the electrical conductivity of all data, $\mathrm{EC}_{\mathrm{m}}$ is the electrical conductivity during the modelling and $\mathrm{EC}_{\mathrm{v}}$ is the electrical conductivity during the validation. According to the soil salinity classification of the Food and Agriculture Organization (FAO), EC values of the study area vary from very strongly saline $(>16 \mathrm{dS} / \mathrm{m})$ to non-saline $(0-2 \mathrm{dS} / \mathrm{m})$. The high coefficient of variation (CV) of $134.78 \%$ confirms the variations of the EC values over the study area. About $65 \%$ of the total samples were classified as saline soil (Douaoui et al., 2006), signifying that this is the dominant soil salinity class.

\section{Regression modelling}

We have 406 samples, from which $80 \%$ was used for modelling and $20 \%$ for validation; the main statistical parameters for EC data are provided in Table 1. The results of correlation between elevation $(z)$ and electrical conductivity (EC) using the five regression models show that soil salinity content decreases gradually as the elevation increases (Wang et al., 2008, Fan et al., 2012, Yahiaoui et al., 2015, Fourati et al., 2017, Wang et al., 2018) as presented in Table 2. These results confirm the ones obtained by Yahaioui et al. (2015), but with a good correlation (RMSE, MAE and $\mathrm{R}^{2}$ ), and according to those values of $\mathrm{R}^{2}$, RMSE and MAE, the superiority of power regression model over the linear, parabolic, exponential, logarithmic regression models in order to estimate EC is proven (Table 2).

Table 1. Descriptive statistics of electrical conductivity (EC)

\begin{tabular}{cccccc}
\hline Type/Statistic & Mean & Max & Min & VC & SD \\
\hline $\mathrm{EC}_{\mathrm{a}}$ & 6.44 & 49.5 & 0.4 & $134.81 \%$ & 8.67 \\
$\mathrm{EC}_{\mathrm{m}}$ & 6.57 & 49.4 & 0.54 & $130.12 \%$ & 8.54 \\
$\mathrm{EC}_{\mathrm{v}}$ & 5.9 & 49.5 & 0.4 & $159.32 \%$ & 9.18 \\
\hline
\end{tabular}

Table 2. Relationship between measured soil EC and elevation using

\begin{tabular}{|c|c|c|c|c|}
\hline Model & Function & RMSE & MAE & $\mathrm{R}^{2}$ \\
\hline linear & $\begin{array}{c}\mathrm{EC}=-0.24 Z+ \\
30.88\end{array}$ & 6.27 & 4.2 & 0.46 \\
\hline parabolic & $\begin{array}{l}\mathrm{EC}=0.01 Z^{2}- \\
1.86 Z+75.83\end{array}$ & 4.6 & 3.1 & 0.71 \\
\hline exponential & $\mathrm{EC}=254.5 \mathrm{e}^{-0.075 Z}$ & 5.18 & 2.38 & 0.88 \\
\hline logarithmic & 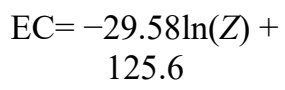 & 5.37 & 3.66 & 0.60 \\
\hline power & $\mathrm{EC}=1 \mathrm{E}+09 Z^{-4,866}$ & 3.48 & 1.59 & 0.92 \\
\hline
\end{tabular}
simple regression.

\section{Ordinary kriging (OK)}

According to the relationship between electrical conductivity (EC) and topography factors (elevation $(Z)$, longitude $(X)$ and latitude $(Y)$ ), the best fitted equation of regression model and values of RMSE, MAE and $\mathrm{R}^{2}$ are provided in Table 3. These results showed that elevation, longitude and latitude explain 53\% of electrical conductivity variability. Thus, it could be concluded that elevation, longitude and latitude are influential parameters affecting conductivity variability in the Lower Cheliff plain region. The elevation, longitude and latitude are easy obtaining factors, and they could be appropriate options for use in the soil salinity modelling. In similar studies, Shahabi et al. (2015) used MLR to estimate the soil salinity.

\section{Multiple linear regressions (MLR)}

The results of the Kolmogorov-Smirnov showed that soil salinity for 325 training samples was not normally distributed; therefore, data were transformed to logarithmic scale. The experimental omnidirectional variogram of the soil EC indicates that the spherical variogram model better suited the soil EC. These spherical models for soil salinity estimation were also used by Shahabi et al. (2016) and Fourati et al. (2017). The semi variogram model parameters for EC are presented in Table 4. The soil of the study area has a high salinity risk. On one hand, the soil with salinity between 4 and $16 \mathrm{dS} / \mathrm{m}$ is dominant in particular in the east and south-east of the study area. On the other hand, the least salted soil $(\mathrm{EC}<4 \mathrm{dS} / \mathrm{m})$ is localized in the east and north-east of the study area, and finally the soil with very strongly saline (EC $>16 \mathrm{dS} / \mathrm{m}$ ) is located in the north-western and south-western area.

Table 3. Properties of the best MLR model

\begin{tabular}{cccccc}
\hline Variable & Model & Function & RMSE & MAE & $\mathrm{R}^{2}$ \\
\hline \multicolumn{5}{c}{$\mathrm{EC}=$} \\
EC & MLR & $\left(-10^{-4} 2.67\right) X+$ & & & \\
& $\left(10^{3} 2.38\right) Y+$ & 5.88 & 3.78 & 0.5 \\
& $(-0.28) Z-$ & & & \\
\hline
\end{tabular}


Table 4. The best fitted semi variogram model parameters for the

\begin{tabular}{cccccc}
\multicolumn{2}{c}{ EC dataset } & & & & \\
\hline Variable & Model & Nugget & Sill & Range & Nuggat/Sill \\
\hline EC & spherical & 0.09 & 0.7 & $7193 \mathrm{~m}$ & 0.12 \\
\hline
\end{tabular}

\section{Artificial neural network (ANN)}

The ANNs have many structures, based on activation function types. In the current study, two types of ANN, namely MLP and RBF, with diverse structures, were used to predict EC. The MLP model with a 3-4-4-1 (elevation $(Z)$, longitude $(X)$ and latitude $(Y)$ ) as inputs and electrical conductivity (EC) as output with two hidden layer) structure was the best model for EC estimation (Fig. 3). The properties of this structure model are provided in Table 5, where HLF is the hidden layer function, NHL is the number of neurons in hidden layer, RMSE is the root mean square error, and MAE is the mean absolute error.

\section{Comparing the results of regression models, ordinary kriging and ANNs}

The overall comparisons between models used to estimate the soil salinization in the current study showed
Table 5. Properties of the best MLP structures with EC as variable ANN HLF NHL RMSE MAE $\mathrm{R}^{2}$

\begin{tabular}{cccccc}
$\begin{array}{c}\text { ANN } \\
\text { (Structure) }\end{array}$ & HLF & NHL & RMSE & MAE & $\mathrm{R}^{2}$ \\
\hline $3-4-4-1$ & tangent & 4 & 0.63 & 0.33 & 0.994 \\
\hline
\end{tabular}

the superiority of MLP over other methods (Table 6), which can be easily confirmed by means of the Taylor diagram in Fig. 4. The Taylor diagram provides a concise statistical summary of how well patterns match each other in terms of their correlation, the ratio of their standard deviations, and their root-mean-square difference (Santos et al., 2019). This diagram is a graphical framework that allows a suite of performance indices of different models to be compared to each other at the same time. Thus, one can note how close the model M8 (MLP) red circle is to the measure red circle.

However, the RBF network demonstrated acceptable accuracy and was more accurate than the regression models and ordinary kriging. Sarani et al. (2015) used artificial neural network to predicting ESP and SAR from $\mathrm{pH}$ and $\mathrm{EC}$ data and reported that the ANN model was better than the regression methods, and Shahabi et al. (2016) showed that MLP could present predictions with less error than MLR and ordinary kriging methods.

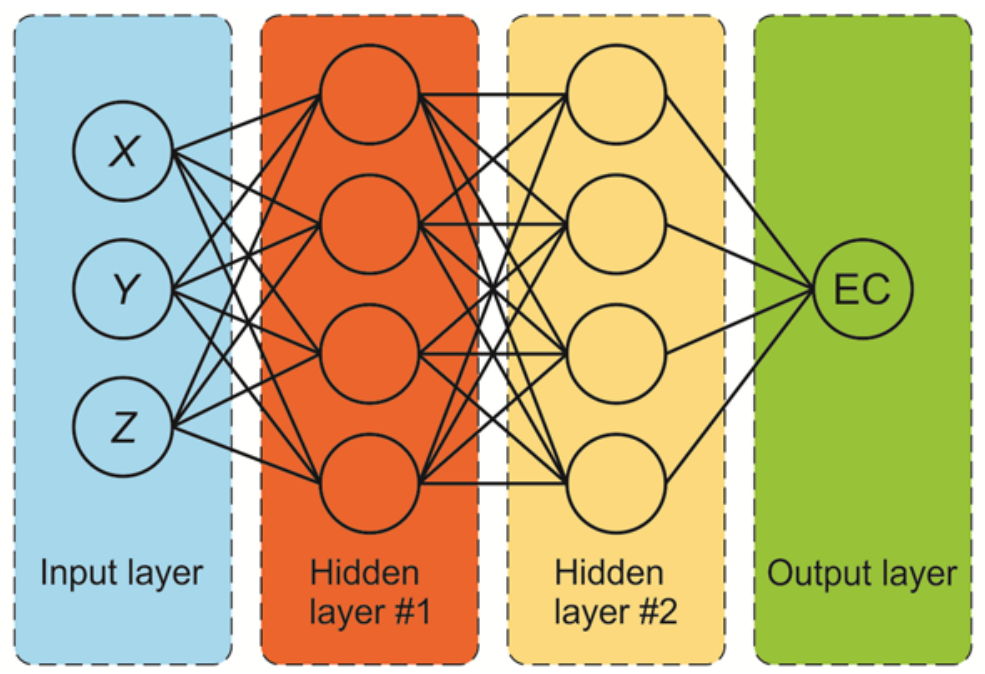

Fig. 3 Schematic of a multilayer perceptron network (MLP).

Table 6. Statistical parameters for the used models of EC

\begin{tabular}{lccccccc}
\hline & \multirow{2}{*}{ Model } & \multicolumn{3}{c}{ Training } & \multicolumn{3}{c}{ Validation } \\
\cline { 2 - 8 } & & RMSE & MAE & $\mathrm{R}^{2}$ & RMSE & MAE & $\mathrm{R}^{2}$ \\
\hline M1 & ordinary kriging & 5.92 & 2.92 & 0.54 & 5.47 & 2.83 & 0.66 \\
M2 & MLR & 5.88 & 3.78 & 0.53 & 7.64 & 4.21 & 0.41 \\
M3 & linear & 6.27 & 4.2 & 0.46 & 8.99 & 5.25 & 0.27 \\
M4 & parabolic & 4.6 & 3.1 & 0.71 & 7.24 & 3.81 & 0.44 \\
M5 & exponential & 5.18 & 2.38 & 0.88 & 5.53 & 2.28 & 0.91 \\
M6 & logarithmic & 5.37 & 3.66 & 0.6 & 7.17 & 4.25 & 0.46 \\
M7 & power & 3.48 & 1.59 & 0.92 & 3.25 & 1.39 & 0.98 \\
M8 & MLP & 0.63 & 0.33 & 0.99 & 0.51 & 0.29 & 0.99 \\
M9 & RBF & 1.74 & 0.97 & 0.96 & 1.67 & 0.97 & 0.97 \\
\hline
\end{tabular}



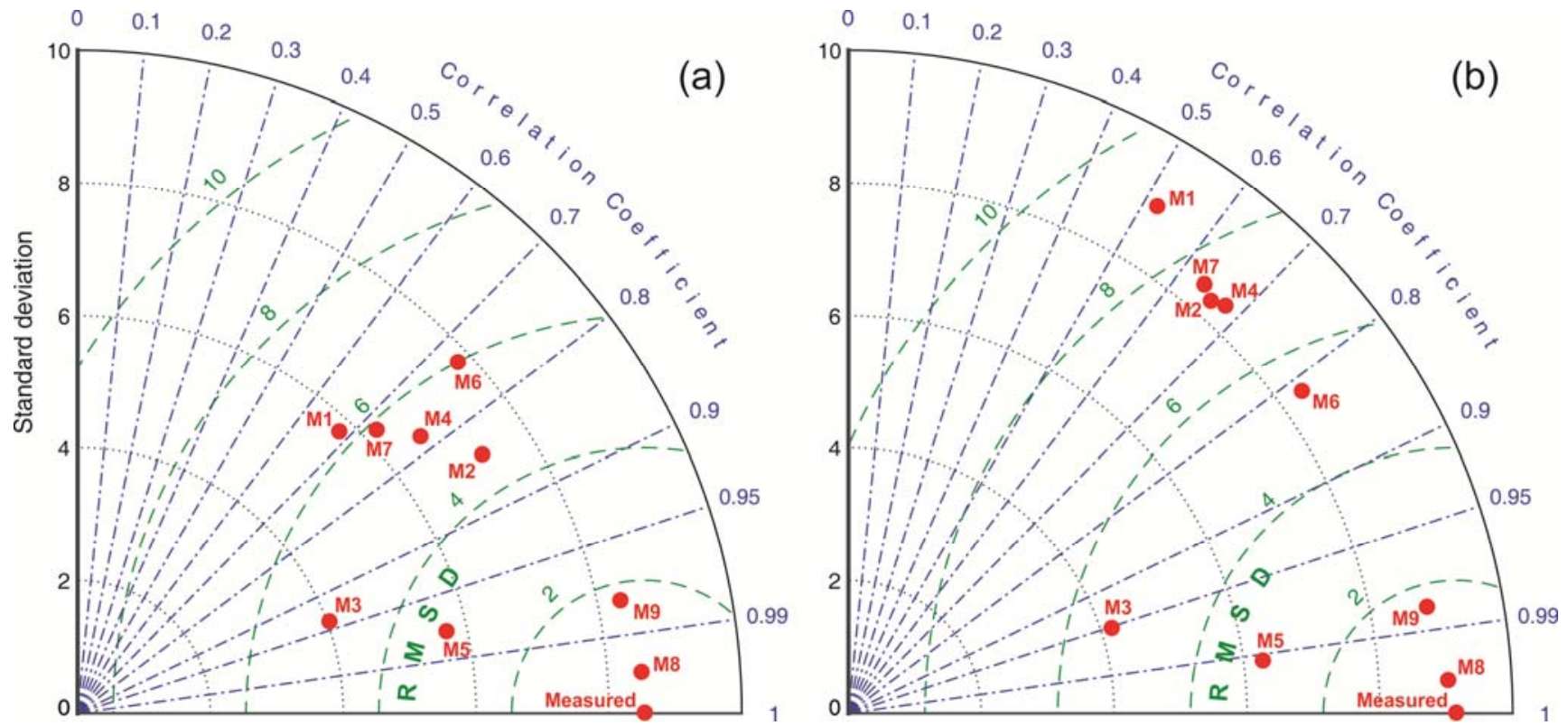

Fig. 4 Taylor diagram for the simulation results (standard deviation, RMSD, and correlation coefficient) of the nine models: M1 (ordinary kriging), M2 (MLR), M3 (linear), M4 (parabolic), M5 (exponential), M6 (logarithmic), M7 (power), M8 (MLP), and M9 (RBF), when compared to the measured EC during the (a) training and (b) validation processes.

The developed MLP model could explain $99 \%$ of the EC variability in the study area, which confirms the superiority of ANNs over regression methods and ordinary kriging in order to model the EC. Figures 5 and $\mathbf{6}$ depict the results between predicted and measured values with the MLP models.

\section{CONCLUSIONS}

The present study aimed to improve the predictive of soil salinity in the Lower Cheliff plain by the analysis of the relationship between measured soil salinity and elevation data. Multiple linear regressions, ordinary kriging and artificial neural network (MLP, RBF) methods were used, and the results showed that the MLP model has superiority in the accuracy of estimating soil salinity values with lower RMSE and MAE and higher Lin's concordance correlation coefficient during modelling and validation.

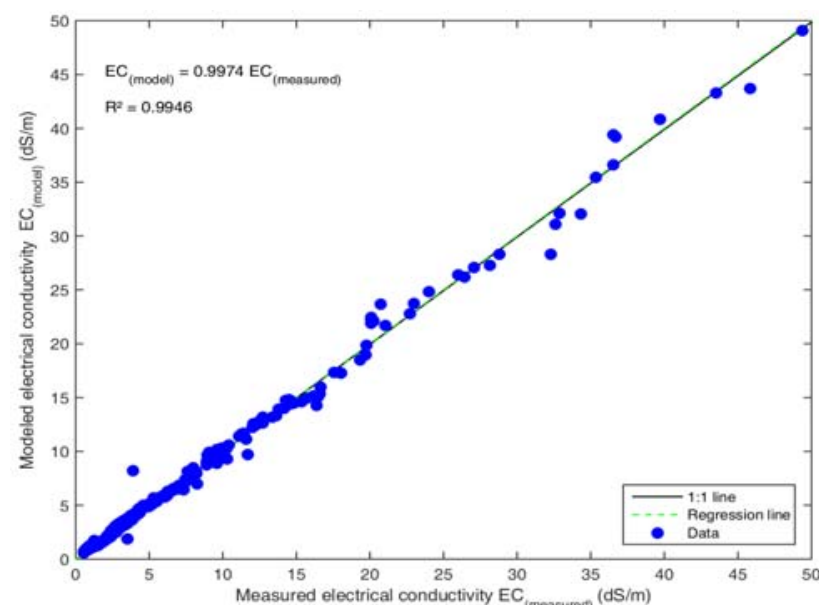

Fig. 5 Scatter plots of estimated vs. measured EC for the training using the MLP.

\section{REFERENCES}

Allbed, A., Kumar, I. \& Aldakheel, Y. (2014) Assessing soil salinity using soil salinity and vegetation indices derived From IKONOS high-spatial resolution imageries: Applications in a date palm dominated region. Geoderma 230-231: 1-8. doi: 10.1016/j. geoderma.2014.03.025

Ayetiguli, S., Shuhe, Z., Yuming, W. (2014) Estimating soil salinity in Pingluo County of China using QuickBird data and soil reflectance spectra. Int. J. Applied Earth Observation and Geoinformation 26, 156-175. doi: 10.1016/j.jag.2013.06.002

Boukhatem, B., Kenai, S., Tagnit, A.H., Ziou, D. \& Ghrici, M. (2012) Predicting concrete properties using neural networks (NN) with principal component analysis (PCA) technique, Comput. Concr. 10(6) 557-573. doi: 10.12989/cac.2012.10.6.557

Douaoui, A. (2005) Variabilité Spatiale de la salinité et sa relation avec certaines caractéristiques des sols de la plaine du BasChéliff. Apport de la géostatistique et de la télédétection .Thèse Doctorat d'état, INA Alger, 233p.

Douaoui, A.E.K., Nicolas, H. \& Walter, C. (2006) Detecting salinity hazards with in a semiarid Context by means of combining soil and remote-sensing data. Geoderma 134(1-2): 217-230. doi:

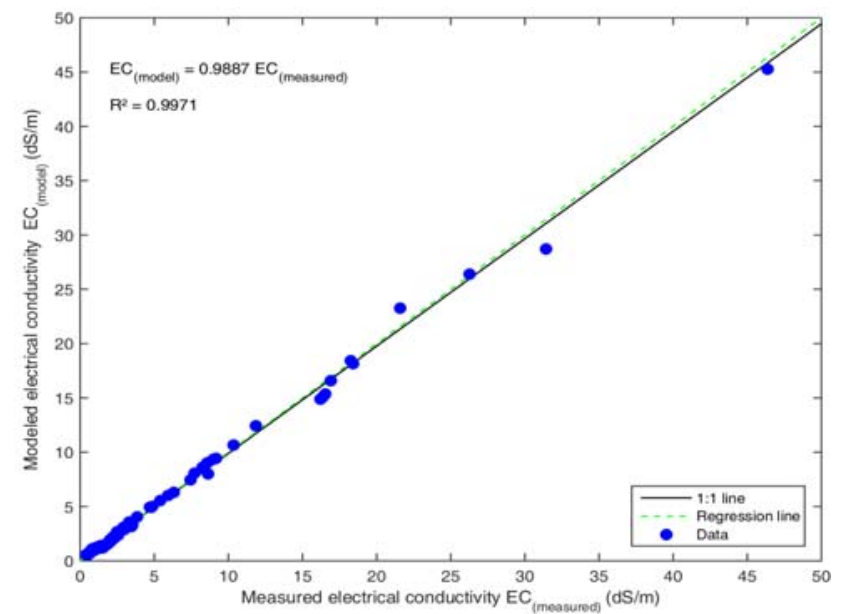

Fig. 6 Scatter plots of estimated vs. measured EC for the validation using the MLP. 
10.1016/j.geoderma.2005.10.009

Dreyfus, G., Martinez, J.M., Samuelides, M., Mirta, B.G., Badran, F., Thiria, S. \& Herault, L. (2002) Réseau de neuronesMéthodologie et application, Ed. Eyrolles, 386p.

Fan, X., Pedroli, B., Liu, G., Liu, Q., Liu, H. \& Shu, L. (2012) Soil salinity development in the yellow river delta in relation to groundwater dynamics. Land Degrad. Develop. 23, 175-189. doi: 10.1002/ldr.1071

Farifteh, J., Van Der Meer, F., Atzberger, C. \& Carranza, E.J. (2007) Quantitative analysis of salt-affected soil reflectance spectra:A comparison of two adaptive methods (PLSR and ANN) Remote Sensing of Environ. 110, 59-78. doi: 10.1016/j.rse.2007.02.005

Fernandez-Buces, N., Siebe, C., Cramb, S. \& Palacio, J. (2006) Mapping soil salinity using a combined spectral response index for bare soil and vegetation: A case study in the former lake Texcoco, Mexico. J. Arid Environments 65, 644-667. doi: 10.1016/j.jaridenv.2005.08.005

Fourati, H.T., Bouaziz, M., Benzina, M. \& Bouaziz, S. (2017) Detection of terrain indices related to soil salinity and mappingsalt-affected soils using remote sensing and geostatistical techniques. Environ Monit Assess. 189:177. doi: 10.1007/s10661017-5877-7

Fourati, HT., Bouaziz, M., Benzina, M. \& Bouaziz, S. (2015) Modeling of soil salinity within a semi-arid region using spectral analysis. Arab. J. Geosci. 8(12): 11175-11182. doi 10.1007/s12517-015-2004-3

Freire, P.K.M.M., Santos, C.A.G. \& Silva, G.B.L. (2019) Analysis of the use of discrete wavelet transforms coupled with ANN for short-term streamflow forecasting. Applied Soft Computing 80, 494-505, doi: 10.1016/j.asoc.2019.04.024

Fuqiang D., Qigang Z., Zhiqiang L., Xuemei W. \& Gangcai L. (2014) Spatial prediction of soil organic matter content integrating artificial neural network and ordinary kriging in Tibetan Plateau. Ecol Indic. 45:184-194. doi: 10.1016/j.ecolind.2014.04.003

Guangming L., Jinbiao L., Xuechen Z., Xiuping W., Zhenzhen L., Jingsong Y., Hongbo S. \& Shipeng Y. (2016) GIS-mapping spatial distribution of soil salinity for Eco-restoring the Yellow River Delta in combination with Electromagnetic induction. Ecological Engng 94 306-314. doi: 10.1016/j.ecoleng.2016. $\underline{05.037}$

Hamzehpour N. \& Bogaert P. (2017) Improved spatiotemporal monitoring of soil salinity using filtered kriging with measurement errors: An application to the West Urmia Lake, Iran. Geoderma 295 22-33. doi: 10.1016/j.geoderma.2017.02.004

Honorato, A.G.S.M., Silva, G.B.L. \& Santos, C.A.G. (2019) Monthly streamflow forecasting using neuro-wavelet techniques and input analysis. Hydrol. Sci. J. 63(15-16), 2060-2075, doi: 10.1080/02626667.2018.1552788

Inakwu, O.A. \& Odeh, A.O. (2008) Spatial Analysis of Soil Salinity and Soil Structural Stability in a Semiarid Region of New South Wales, Australia. Environmental Management 42:265-278. doi: 10.1007/s00267-008-9100-Z

Jianli, D. \& Danlin, Y. (2014) Monitoring and evaluating spatial variability of soil salinity in dry and wet seasons in the WeriganKuqa Oasis, China, using remote sensing and electromagnetic induction instruments. Geoderma 235-236: 316-322. doi: 10.1016/j.geoderma.2014.07.028
Metternicht, G.I. \& Zinck, J.A. (2003) Remote sensing of soil salinization: potentials and constraints. Remote Sensing of Environ. 85:1-20. doi: 10.1016/S0034-4257(02)00188-8

Ping, Z., Jingsong, Y., Jianrong, F., Guangming, L. \& Dongshun, L. (2010) Artificial neural network and time series models for predicting soil salt and water content. Agricultural Water Management 97: 2009-2019. doi: 10.1016/j.agwat.2010.02.011

Quan, W., Pingheng, L. \& Xi, C. (2012) Modeling salinity effects on soil reflectance under various moisture conditions and its inverse application: A laboratory experiment. Geoderma 170, 103-111. doi: 10.1016/j.geoderma.2011.10.015

Rhoades, J.D. (1982) Reclamation and management of salt-affected soils after drainage. Proc. First Annual Western Prov. Conf. Rationalization of Water and Soil Resources and Management, Alberta, USA.

Rumelhart, D.E., Hinton, G.E. \& Williams, R.J. (1986) Learning internal representations by error propagation. In Parallel Distributed Processing.

Santos, C.A.G \& Silva, G.B.L. (2014) Daily streamflow forecasting using a wavelet transform and artificial neural network hybrid models. Hydrol. Sci. J. 59(2), 312-324, doi: 10.1080/02626667. 2013.800944

Santos, C.A.G., Freire, P.K.M.M., da Silva, R.M. \& Akrami, S.A. (2019) Hybrid wavelet neural network approach for daily inflow forecasting using tropical rainfall measuring mission data. $J$. Hydrol. Engng 24(2), 04018062, doi: 10.1061/(asce)he.1943$\underline{5584.0001725}$

Sarani, F., Ahangar, A.G. \& Shabani, A. (2015) Predicting ESP and SAR by artificial neural network and regression models using soil $\mathrm{pH}$ and EC data (Miankangi Region, Sistan and Baluchestan Province, Iran). Archives of Agronomy and Soil Science 62(1), 127-138. doi: $10.1080 / 03650340.2015 .1040398$

Scudiero, E., Skaggs, T.H. \& Corwin, D.L. (2017) Simplifying fieldscale assessment of spatiotemporal changes of soil salinity. Science of the Total Environ. 587-588, 273-281. doi: 10.1016/j. scitotenv.2017.02.136

Shahabi, M., Jafarzadeh, A.A., Neyshabouri, M.R., Ghorbani, M.A. \& Kamran, K.V. (2016) Spatial modeling of soil salinity using multiple linear regression, ordinary kriging and artificial neural network methods. Archives of Agronomy and Soil Science 63(2), 151-160. doi: 10.1080/03650340.2016.1193162

Wang, Y, Deng, C., Liu, Y., Niu, Z. \& Li, Y. (2018) Identifying change in spatial accumulation of soil salinity in an in-land river watershed, China. Science of the Total Environ. 621, 177-185. doi: $10.1016 /$ j.scitotenv.2017.11.222

Wang, Y., Li, Yan \& Xiao, D. (2008) Catchment scale spatial variability of soil salt content in agricultural oasis, Northwest China. Environ Geol. 56(2), 439-446. doi: 10.1007/s00254-007$\underline{1181-0}$

Yahiaoui, I., Douaoui, A., Zhang, Q. \& Ziane, A. (2015) Soil salinity prediction in the Lower Cheliff plain (Algeria) based on remote sensing and topographic feature analysis. J Arid Land. 7(6), 794805. doi: $10.1007 / \mathrm{s} 40333-015-0053-9$

Yang, B.D.S., Park, S.K. \& Lee, J.H. (2003) A prediction on mix proportion factor and strength of concrete using neural network, KSCE J. Civil Engng 7(5), 525-536 